\title{
A new approach to solve the distribution system planning problem considering automatic reclosers
}

\author{
Nuevo enfoque para resolver el problema de planeamiento de sistemas de \\ distribución considerando reconectadores automáticos
}

Oscar D. Montoya G..$^{*} \quad$ Alejandro Grajales O. ${ }^{1} \quad$ Ricardo A. Hincapié I. ${ }^{1} \quad$ Mauricio Granada E. ${ }^{1}$

Received: april 27, 2016, Accepted: Septiembre 1, 2016

Recibido: 27 de Abril de $2016 \quad$ Aceptado: 1 de Septirmbre de 2016

\begin{abstract}
This article describes two new methodologies for optimal distribution system planning considering automatic reclosers to improve reliability indices. The first methodology proposed in this paper employs a two-stage cascade strategy to solve the problem. In the first stage a mono-objective Tabu Search (TS) algorithm is used to find the optimal distribution system topology. The installation cost of new elements, increasing capacity on existing elements and operational costs associated with technical losses are considered. In the second stage a Non-Dominated Sorting Genetic Algorithm known as NSGA II is employed, considering the optimal distribution system topology found by the first stage, and thus, solving the problem of optimal location of automatic reclosers in distribution systems. The non-supplied energy level of the network and installation cost of reclosers are considered as objective functions; and the min-max criterion to select a point on the optimal Pareto front is used. In the second methodology, a master-slave based optimization algorithm is used to find the best network topology including the associated to automatic reclosers. Master algorithm is a TS algorithm which is responsible to direct the optimization process through solution space, whereby, for each neighbor generated, the slave algorithm NSGA II is applied and min-max criterion is used to determine a configuration of reclosers for actual network topology. The proposed methodologies are applied on three-phase version of IEEE 34 nodes test feeder, with high quality results.
\end{abstract}

Keywords: Distribution systems, min-max criterion, multi-objective optimization, NSGA-II Algorithm, reclosers, reliability.

\section{RESUMEN}

En este artículo se presentan dos nuevas metodologías para la planeación óptima de sistemas de distribución considerando la inclusión de reconectadores automáticos para mejorar los indicadores de confiabilidad. La primera metodología propuesta en este trabajo emplea una estrategia en cascada de dos etapas para resolver el problema. En la primera etapa se utiliza el algoritmo de optimización monoobjetivo Búsqueda Tabú (TS) para encontrar la topología óptima del sistema de distribución, en el que se consideran el costo en la instalación de nuevos elementos, el aumento de capacidad en los elementos existentes y los costos operativos de la red asociados a las pérdidas técnicas. En la segunda etapa es empleado el algoritmo genético de ordenamiento no dominado conocido como NSGA II, considerando la topología óptima encontrada en la primera etapa, para solucionar el problema de ubicación óptima de reconectadores automáticos en el sistema de distribución. Como funciones objetivo se considera el

\footnotetext{
1 Universidad Tecnológica de Pereira. Carrera 27 \#10-02 Barrio Álamos Pereira, Colombia.

E-mail: o.d.montoyagiraldo@ieee.org; agrajales@utp.edu.co; ricardohincapie@utp.edu.co; magra@utp.edu.co

* Autor de correspondencia
} 
nivel de energía no servida de la red y el costo de instalación de los reconectadores; y es empleado el criterio min-max para seleccionar un punto sobre el frente óptimo de Pareto. En la segunda metodología propuesta un algoritmo de optimización del tipo Maestro-Esclavo es empleado para encontrar la mejor topología de la red incluyendo los reconectadores automáticos asociados a esta. El algoritmo maestro es el TS quien es el encargado de guiar el proceso de optimización por el espacio de solución, con lo que para cada vecino generado se aplica el algoritmo esclavo NSGA II y el criterio min-max con el que se selecciona una configuración de reconectadores para la topología actual de la red. Las metodologías propuestas son aplicadas sobre una versión trifásica del sistema IEEE 34 nodos, con resultados de muy buena calidad.

Palabras clave: Sistemas de distribución, criterio min-max, optimización multiobjetivo, algoritmo NSGA II, reconectadores, confiabilidad.

\section{NOMENCLATURE}

Sets

$\Omega_{b}$

Set that defines the feasible combinations for phase balancing.

Set of possible type of wires associated to

$\Omega_{c}$

$\Omega_{d}$

$\Omega_{D}$

$\Omega_{i j}$

$\Omega_{H}$

$\Omega_{T}$

$\Omega_{k}$

$\Omega_{k E}$

$\Omega_{k S}$

$\Omega_{i j N}$

$\Omega_{Y}$

$\Omega_{y N}$

$\Omega_{y L}$

\section{Parameters and sub-indices}

b

$c, e$

$d, f$

$C_{m}$

CAC

$C A S^{d}$

$C B F^{k}$

$\mathrm{CCC}^{\mathrm{c}}$

$\mathrm{CNC}^{\mathrm{c}}$

the lines.

Set of candidate substations for repowering and installation.

Set of all the possible locations of normally open and normally closed reclosers of the system. Set of all the routes of the system.

Set that contains the discretized load curve.

Set that contains all the years of the planning period.

Set of all the nodes of the system.

Subset of $\Omega_{k}$ that contains the existing nodes of the system.

Subset of $\Omega_{k}$ that contains the candidate nodes for location of substation in the system.

Subset of $\Omega_{i j}$ that contains all the lines connected of the system.

Set of operative areas of the system.

Set of nodes of the operative area $y$, where $y \Omega_{Y}$.

Set of lines of the operative area $y$, where $y \Omega_{Y}$.

Index that defines the type of balance in the node $k$.

Index that defines the type of wires available.

Index that defines the type of substation available.

Installation cost of the recloser $m$.

Cost of opening an existing line in the route $i j$.

Cost of repowering substation in the node $k$ with one type $d$.

Investment cost of phase balancing in the node $k$. Investment cost of rewiring in the route $i j$, with wire type $c$.

Investment cost of new wire in the route $i j$, with wire type $c$.
$C N S^{d}$

$C_{k W h}$

$F_{1}$

$F_{2}$

$H^{h}$

$h$

$I_{i j, \max }^{c, \max }$

$i j, a b c$

$I_{i j}^{c, \text { max }}$

$i_{a}$

$i_{e}$

$i_{i j}$

$k$

$L_{i j}$

$L_{i j, y}$

$N_{i j E}$

$N_{k}$

$N_{d E}$

$P_{k, y}$

$P_{k, a b c}^{D}$

$S_{k, a b c}^{D}$

$S_{k, a b c}^{D}$

$r_{i j, y}$

$R_{i j, a b c}^{c}$

$T$

$t$

$V_{k, a b c}^{\max }$
Investment cost of installing a new substation in the node $k$ with one of type $d$.

Cost of energy (USD/kW-h).

Factor that brings to present value the cost of the energy losses.

Factor that annualizes the costs over the planning horizon.

Number of hours of the planning period $h$.

Index that defines the number of discretized periods of the year.

Maximum current capacity of the network segment $i j$ with wire type $c$ in three-phase case.

Maximum current capacity of the network segment $i j$ with wire type $c$ in single-phase case.

Discount rate to bring costs to present value. Growth rate of energy.

Index that defines the routes of the system. Index that defines the nodes of the system.

Length of the branch $i j$.

Length of the branch $i j$ belonging to the area $y$. Total number of existing lines of the system. Total number of nodes of the system.

Total number of substations of the system.

Active power demanded in the node $k$ belonging to the area $y$.

Active power demanded in the node $k$ in three-phase case.

Reactive power demanded in the $k$ in threephase case.

Apparent power demanded in the node $k$ in three-phase case.

Mean repair time of a permanent failure in the network segment $i j$ belonging to the area $y$.

Conductor resistance of type $c$.

Total years of the planning period.

Index that defines years of the planning period.

Maximum voltage permitted in the node $k$ in the three-phase case. 
$V_{k} \max \quad$ Minimum voltage permitted in the node $k$ in the three-phase case.

$V_{k}^{\max } \quad$ Maximum voltage permitted in the node $k$ in the single-phase case.

$V_{k}^{\min } \quad$ Minimum voltage permitted in the node $k$ in the single-phase case.

$\lambda_{i j, y} \quad$ Permanent failure rate in the network segment $i j$ belonging to the area $y$.

$\lambda_{i j}^{c} \quad$ Parameter that defines whether there is a type $c$ conductor in the network segment $i j$.

$\lambda_{k}^{d} \quad$ Parameter that defines whether there is a type $d$ substation in the node $k$.

$\lambda_{k}^{b} \quad$ Parameter that defines the type of phase $k \quad$ balancing $b$ in the node $k$.

$\gamma_{k} \quad$ Parameter that indicates the phase connection $\gamma_{k} \quad$ in the node $k$.

\section{Binary variables}

$\delta_{i j}^{c}$

Decision variable that indicates whether the type $c$ conductor is located at the network segment $i j$.

$\delta_{k}^{d} \quad$ Decision variable that indicates whether type $k \quad d$ substation is located in the node $k$.

$u_{k}^{b} \quad$ Decision variable that indicates whether phase $\mu_{k} \quad$ balancing is done in the node $k$.

Decision variable that whether an automatic recloser is located in the position $m$.

All binary variables take the value of one (1) if action is done; and zero (0) otherwise.

\section{Continue variables}

$I_{i j, a b c}^{h} \quad$ Current through the network segment $i j$ in the sloss Apparent power losses in the network segment

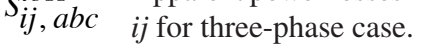

$I_{k} E \quad$ Apparent power supplied by the substation $I_{k, a b c} \quad$ located in the node $k$ for three-phase case.

$V_{k}^{h} \quad$ Voltage in node $k$ in period of time $h$ for $V_{k, a b c}$ three-phase case.

$V_{h} \quad$ Voltage in node $k$ for single-phase case.

$\theta_{k}^{h} \quad$ Voltage angle in node $k$ in period of time $h$ for $\theta_{k, a b c}$ three-phase case.

$\theta_{h} \quad$ Voltage angle in node $k$ for single-phase case.

\section{INTRODUCTION}

The growth of trade exchanges and the massification of production processes at industrial level, are demanding a fundamental support to electrical systems to achieve the goals of economic growth in emerging countries, and thus, compete in today's globalized world. Therefore, each country generates regulatory policies applicable to the electrical system in order to find efficient models that guarantee quality and reliability of power supply to all system users [1].

On the other hand, the technological age has fostered the electricity consumption in every household and thus there have been overall growth in consumption habits, while recognizing that policies for the rational use of energy have uncongested, to some extent, electrical systems. However, by adding the above phenomena, it is clear that the electrical system is constantly evolving, for which it requires the existence of efficient and reliable expansion models to predict demand increases at medium and at long term periods, and thereby make electrical systems fit for changes into projected consumption, including compliance with all regulatory aspects in terms of quality and continuity of service [2].

Innumerable papers related to the optimal expansion of distribution systems in the specialized literature can be found. Most of them are related to the solution of the classical model, i.e. decoupling the problem of expansion of systems or long-term model and the operating problems related to the quality and continuity of power supply or short-term operating model. Next, the most relevant papers in this regard are highlighted.

In [3], a multi-objective and colony optimization algorithm to solve the Distribution System Planning Problem (DSPP) is presented. Reliability (System Average Interruption Frequency Index SAIFI) and planning cost are considered as objective functions by the algorithm. In [4], a methodology to solve DSPP employing a multi-objective TS, in what they call fuzzy distribution system planning is presented. Three objective functions simultaneously are considered: project cost, reliability and robustness of system.

In [5], different mathematical models for the expansion and operation of the power systems, taking into account protective devices and distributed generators, are presented. The methodology considers two stages: the first stage determines a possible solution for DSPP. The second stage locates a set of protective devices to minimize the Non-Supplied Energy Level (NSEL) of the network. For this propose, a multi-objective NSGA II is employed. 
In the same year, a multi-objective particle swarm optimization algorithm (PSO) with two stages to solve the DSPP is developed [6]. The First stage defines the system topology, i.e., substations, lines with their wire gauges, and the candidate points to locate sectionalizers. At the second stage, optimal number of transference lines is determined. The objectives considered are: minimization of investment and system operation costs, and maximization of reliability through reduction of NSEL.

In [7], a cascade methodology to solve the DSPP through a Simulated Annealing (SA) is shown. Once the best topology is obtained, a NSGA II is used to find the Pareto front that minimizes the non-supplied energy of the system and the investment costs [8]. The developed model is applied to distribution systems with three-phase representation. This methodology allowed to find good results.

Unlike previous works, this paper presents two methodologies to solve the DSPP and Problem of Optimal Location of Automatic Reclosers in Distribution Systems (POLARDS) in a simultaneous way. In DSPP formulation, a three-phase system model is used. A mono-objective formulation that considers the substations and new branches investment costs is developed. This formulation also considers the investment costs of substation enlargements and wire gauge changes, in addition to the operating costs of the system over the planning horizon, taking into account the operating conditions of the classical model. To solve this problem, a TS algorithm is employed [9], in which it is included a Chu \& Beasley Genetic Algorithm (CBGA) as local improvement phase to minimize power losses by using phase balancing [10].

On the other hand, POLARDS formulation is developed employing a multi-objective model. This model considers a one-phase system representation and has as objective functions the NSEL minimization and investment costs for automatic reclosers. The first objective function uses the optimal location of normally closed reclosers (NCR) for fault isolation and normally opened reclosers (NOR) for load transference. To solve this problem, a NSGA II algorithm is used [8].

The first proposed methodology is a cascade optimization scheme in which a TS algorithm is used to solve the DSPP and then a NSGA II algorithm is employed to solve the POLARDS. The second proposed methodology is an integrated master-slave based scheme in which TS algorithm is the master and NSGA II is the slave. To validate the suggested models, a comparison between the two methodologies is done and a new test system with unbalanced loads and similar characteristics to the behavior of Colombian power systems is proposed [11].

\section{GENERAL PROBLEM FORMULATION}

To represent the DSPP and POLARDS in an appropriate way, two mathematical models are developed. The first model is a mono-objective representation of the DSPP [11]. The second model is a multi-objective representation of the POLARDS [8].

\section{Formulation of DSPP}

The DSPP has its origin in the need to address timely and adequately the demand growth, for which it requires the efficient expansion of the system, which is achieved through the construction of new branches and substations or expanding capacity of existing elements. Equations (1) to (9) represent a non-linear integer mixed model, used to model the DSPP $[9,11]$.

Equation (1) corresponds to the objective function: the first and second terms represent the construction of new branches and expanding capacity of existing branches, respectively. The third factor represents the investment costs in power losses during the study period. The fourth term accounts for the cost of opening an existing network to let it out of operation. The fifth and sixth factors correspond to the construction of substations and enlargement of existing substations, respectively. Finally, the seventh term represents the cost of phase balancing in existing branches. The model calculates the total costs in present value and then, it is annualized over the planning period. Additionally, note that several terms of the objective function relate the parameters $\lambda$ and the decision variables, activating or canceling a cost associated to an element.

Regarding to the constraints, equation (2) corresponds to compliance with the power balance on each node in the system; equations (3) and (4) ensure the 
meeting of the capacity limits of current transfer in all sections of network and voltage regulation limits on all nodes of the system, respectively. Equation (5) ensures that new and existing substations do not exceed their power injection capacity limits. Equation (6) corresponds to the condition of radial operation system which operates in conjunction with (2). Equations (7) and (8) define the binary characteristic of the decision variables, and finally, equations (9) and (10) correspond to the factors for calculating the power losses during the study period and the annualization factor of costs, respectively.

\section{Solution technique for DSPP}

To solve the DSPP, a TS algorithm is used. This metaheuristic is able to achieve good results in solving such problems [10-11].

$$
\min z_{1}\left[\begin{array}{l}
\sum_{i j \in \Omega_{i j}} L_{i j} \cdot\left(\sum_{c \in \Omega_{c}} \lambda_{i j}^{c}\left(1-\delta_{i j}^{c}\right)\left(\sum_{c \in \Omega_{c}} \delta_{i j}^{c} \cdot C C C^{e}\right)\right) \\
+\sum_{i j \in \Omega_{i j}} L_{i j} \cdot\left(\sum_{c \in \Omega_{c}} \delta_{i j}^{c}\left(1-\sum_{e \in \Omega_{c}} \lambda_{i j}^{e}\right) C N C^{c}\right) \\
+F_{1} \cdot \sum_{i j \in \Omega_{i j}} L_{i j} \cdot\left(\sum_{c \in \Omega_{c}} \delta_{i j}^{c} \cdot \sum_{h \in H} H^{h} R_{i j j_{b c}}^{c} I_{i j_{a b c}}^{h}\right) \\
+\sum_{i j \in \Omega_{i j}} \delta_{c \in \Omega_{c}} \delta_{i j}^{e}\left(\sum_{c \in \Omega_{c}} \lambda_{i j}^{e}\right) C A C \\
+\sum_{k \in \Omega k T} \sum_{d \in \Omega_{d}} \lambda_{k}^{d}\left(1-\delta_{k}^{d}\right)\left(\sum_{f \in \Omega d} \delta_{k}^{f} \cdot C A S^{f}\right) \\
+\sum_{k \in \Omega k T} \sum_{d \in \Omega_{d}} \delta_{k}^{d}\left(1-\sum_{f \in \Omega d} \lambda_{k}^{f}\right) C N S^{d} \\
+\sum_{k \in \Omega k E} \sum_{b \in \Omega} \gamma_{k}^{b}\left(1-\mu_{k}^{b}\right) C B F_{k}
\end{array}\right] \cdot F_{2}
$$

s.t.

$$
\begin{gathered}
E Q^{u}\left(P_{k, a b c}^{D}, Q_{k, a b c}^{D}, V_{k, a b c}^{h}, \theta_{k, a b c}^{h}\right)= \\
0 \forall k \in \Omega_{k} \forall h \in \Omega_{H} \\
\left|I_{i j, a b c}^{h}\right| \leq I_{i j, a b c}^{c, \max } \quad \forall i j \in \Omega_{i j} \quad \forall h \in \Omega_{H} \\
V_{k, a b c}^{\min } \leq V_{k, a b c}^{h} \leq V_{k, a b c}^{\max } \forall k \in \Omega_{k} \quad \forall h \in \Omega_{H} \\
\sum_{k \in \Omega_{k}} S_{k, a b c}^{D}+\sum_{i j \in \Omega_{i j}} S_{i j, a b c}^{l o s s} \leq \sum_{k \in \Omega_{k S}} S_{k, a b c}^{S E} \quad \forall h \in \Omega_{H}
\end{gathered}
$$

$$
\begin{gathered}
N_{i j E}+\sum_{i j \in \Omega_{i j N}} \sum_{c \in \Omega_{c}} \delta_{i j}^{c} \leq N_{k}-N_{d E}-\sum_{k \in \Omega_{k S}} \sum_{d \in \Omega_{d}} \delta_{k}^{d} \\
\sum_{c \in \Omega_{c}} \delta_{i j}^{c} \leq 1 \quad \forall_{i j} \in \Omega_{i j} \\
\sum_{d \in \Omega_{d}} \delta_{k}^{d} \leq 1 \quad \forall k \in \Omega_{k} \\
F_{1}=\left(\frac{C_{k W h}}{1000}\right) \cdot \sum_{t \in \Omega_{T}}\left(\frac{1+i_{e}}{1+i_{a}}\right)^{t} \\
F_{2}=\frac{i_{a} \cdot\left(1+i_{a}\right)^{T}}{\left(1+i_{a}\right)^{T}-1}
\end{gathered}
$$

For better explanation see $[9,11]$. TS algorithm allows to find optimal configurations or solutions of good quality in combinatorial and highly complex problems (non-differentiable and nonconvex problems with mixed variables), where the solution space grows exponentially with the size problem [12]. In general, TS algorithm solves mono-objective problems of type $\min f(x) ; s . a .\left\{h(x)=0^{\wedge} g(x) \leq 0\right\}$.

TS algorithm performs a search for the solution space through a travel path, as a local search heuristic algorithm is done [11]. Thus, for an initial configuration $x^{t}$, the neighborhood is defined $N\left(x^{t}\right)$ as the set of adjacent elements to $x^{t}$ such that $x^{t} \in$ $N\left(x^{t}\right)$. This set of neighborhood can be obtained by using guided heuristic strategies or random generation processes. However, TS algorithm differs from a local search heuristic algorithm on three essential aspects.

The first aspect is the selection of the next configuration $x^{t+1}$ for which the best neighbor found is selected, considering that $x^{t+1}$ has a better adaptive function than the configuration $x^{t}$ (applying aspiration criteria). Otherwise, the individual that has less blocked attributes in the neighborhood by the tabu criteria is selected, allowing degradations in the adaptation function (in order to escape from local solutions).

The second essential aspect is to employ short and long term memories, which prevent the search return to previously explored solution spaces in local 
search. Finally, as a third aspect, a strategy reset to start again local search is used, which seeks to explore the solution space from different starting points, to reach a solution and ensure good quality. This solution is contained in the elite list, which stores the best solutions obtained at local searches on the first and second steps of this algorithm, as shown in Figure 1 [11].

In TS algorithm there are other strategies of advanced search [9], among which the strategic oscillation and path relinking are detailed and implemented in [13].

\section{Initial topology for DSPP}

In order to understand the methodology that generates the initial topologies or starting points to solve

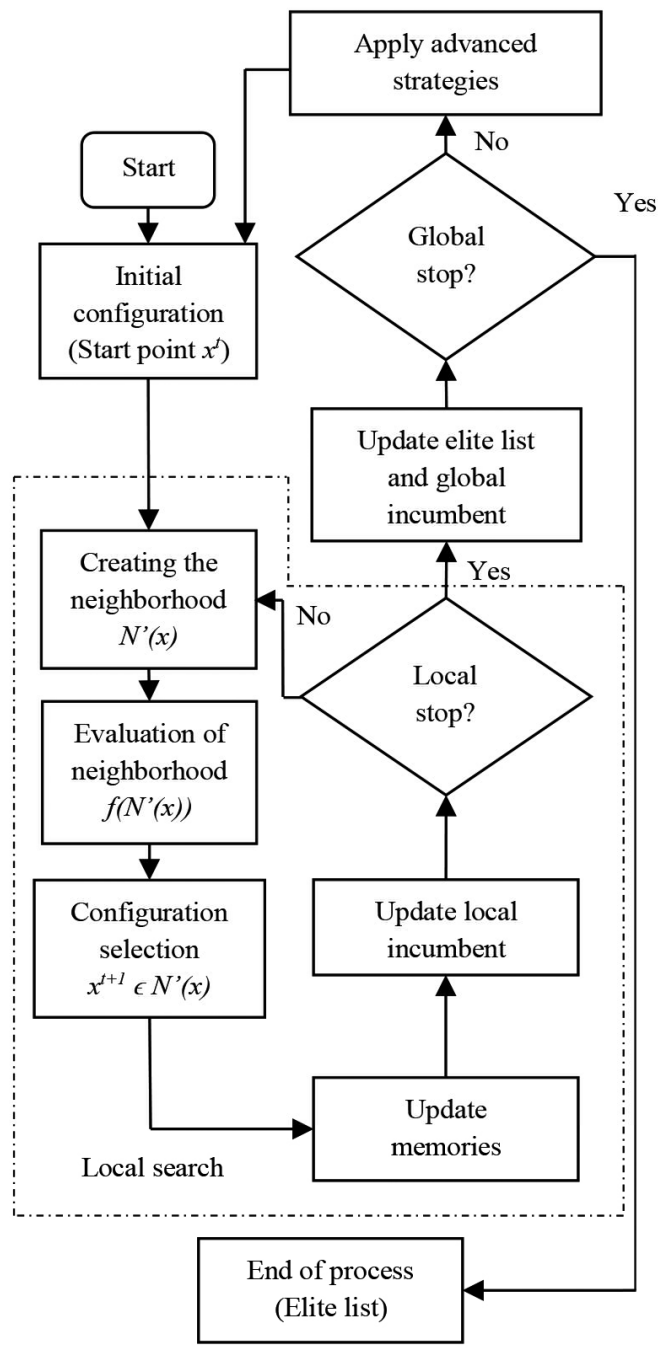

Figure 1. TS algorithm [11]. the DSPP, consider the classic configuration of a distribution system for planning the expansion, as presented in Figure 2.

The total power of this system is 35.4 MVA and the existing substation is of type 1 with an installed capacity of 20 MVA. All substations can be of type 1 or type 2 , where type 2 has a rated capacity of 30 MVA. In Figure 2, solid lines represent existing elements at the beginning of the planning period, and dashed lines represent potential network expansions. Also, the continuous and dotted squares correspond to existing substations and proposals, respectively. Finally, the circular nodes correspond to load points or waypoints of the distribution system.

In order to make efficient the process of optimization algorithm, in each local search the feasibility of selected substations configuration is assured, that is, that can supply the global demand plus power losses. To achieve this, a binary combination of substations, which in the case of Figure 1 corresponds to three substations, generates seven combinations ranging from $\{0,0,0\}$ to $\{1,1,1\}$. From this set of combinations, the selected combinations are those in which the summation of their maximum capacities is greater than the rated value and guarantee that the substation is not eliminated.

In the case of Figure 2, the substations are arranged as $\{10,11,12\}$, and feasible combinations are $\{1$, $0,1\},\{1,1,0\}$ and $\{1,1,1\}$. Finally, many local searches are performed, as existing substations configurations are feasible, generating diversity in the global search as initialization points on the solution space are different. During the local search is not allowed to remove substations, that is, local search retains the source nodes whith which the process of optimization is started with [11].

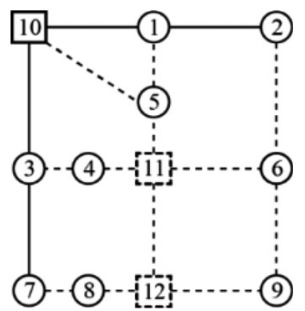

Figure 2. Topology to explain the DSPP. 
For the generation of the initial configuration of TS, two constructive heuristic algorithms are employed [14]. The first heuristic algorithm corresponds to a tree of minimum weight (Kruskal algorithm) which consists of two strategies for tree generation. The initial network topology is used and from this the tree is constructed or built from the minimum weight, assuming that there is not anything constructed. For both cases the lengths of network sections are considered as weights. The second method is a random generation strategy, where a branch is selected randomly to be part of the tree in each iterative process [11]. Once the tree is constructed, the connections formed between substations are removed through a selection algorithm that determines the longest network segment that links the substations and make them to get disconnected, with which radial configurations for each substation are obtained.

Finally, wire gauges are selected through a Backward/ Forward Sweep Power Flow [15], considering that at the beginning all network sections have top gauges available for system installation. Once the currents in each network segment are calculated, gauges are reallocated, ensuring as possible a telescopic configuration in the network. Finally, a CBGA is employed to perform the phase balancing in order to reduce power losses in the system [10].

All the process described above, provides the initial configuration of the DSPP.

\section{Neighborhood criteria}

For generating neighboring configurations to the current configuration $x^{t}$ forming the neighborhood $N\left(x^{t}\right)$, three different strategies are employed.

The first of them is changing the capacity at existing substations. This criterion is applied once it is detected that the capacity of the substations is below the system demand plus the power loss, thereby exploration guarantees space through the feasibility [11].

The second generation strategy is the selection of those branches with poor voltage regulation. In this manner, a type of gauge is reassigned, ensuring that the network remains in telescopic configuration, seeking to reduce power loss and improve voltage regulation.
The third strategy is called Branch Exchange and for this work, two alternatives are considered: the first one is a reconfiguration taking into account the differential voltage in which the disconnected lines with the greatest voltage differential at their terminals are selected, then, the line belonging the extreme with the worst voltage profile is disconnected [7]. The second case involves a random exchange of branches in which a disconnected branch is selected to enter into operation and randomly an active branch is selected to be removed, guaranteeing radial topologies. Finally, through a reassignment strategy of wire gauges, the telescopic configuration of the networks is guaranteed [11].

The global set of neighbors is formed by a portion of individuals obtained in each neighborhood strategy and to which the CBGA for phase balancing is applied as a local improvement method [10].

\section{Stopping criteria}

To determine the end of each process of local search two criteria are used. The first one corresponds to the limit of generations of each search defined in the configuration of the TS algorithm and the second one uses the number of times that the algorithm does not improve the local incumbent, which determines whether the process should end. The best solution found in local search is stored in the global elite list [9].

To determine the number of reboots or local searches the number of feasible configurations for substations in which each of them performs a local search is used. The process concludes when these configurations have been analyzed and the response corresponds to the best solution found in each of the local search [11].

\section{Problem codification}

To represent adequately the DSPP a codification vector compound by three structures is employed. The first structure is the type of conductor used for each network segment; the second structure corresponds to the capacity of the substations and the third structure is the phase balancing, as shown in Figure 3.

The size of vector encoding is $c^{*} N_{i j}+d^{*} N S E_{k}$ $+b * N_{b}$, where $N_{i j}$ is the total number of network segments, $c$ is the number of line gauges, $N S E_{k}$ is 


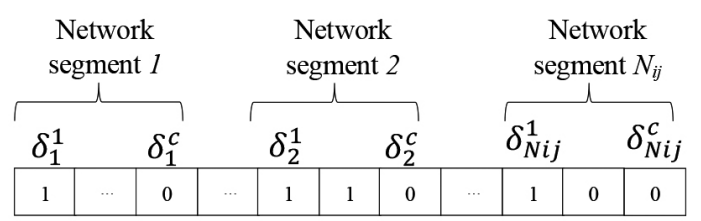

a) Codification for conductors

\begin{tabular}{|c|c|c|c|c|c|c|c|c|c|}
\hline \multicolumn{2}{|c|}{ Node $N_{S E I}$} & \multicolumn{4}{|c|}{ Node $N_{S E 2}$} & & \multicolumn{3}{|c|}{$N_{\text {SEK }}$} \\
\hline$\delta_{S E 1}^{1}$ & $\delta_{S E 1}^{d}$ & & $\delta_{S E 2}^{1}$ & & $\delta_{S E 2}^{d}$ & & $\delta_{S E}^{1 N}$ & & $\delta_{S E k}^{d}$ \\
\hline 1 & 0 & $\ldots$ & 1 & 1 & 0 & & 1 & 0 & 0 \\
\hline
\end{tabular}

b) Codification for substations

\begin{tabular}{|c|c|c|c|c|c|c|c|c|c|c|}
\hline \multicolumn{3}{|c|}{ Node 1} & & \multicolumn{3}{|c|}{ Node 2} & & \multicolumn{3}{|c|}{ Node $N_{b}$} \\
\hline$\delta_{1}^{1}$ & & $\delta_{1}^{b}$ & & $\delta_{2}^{1}$ & & & & $\delta_{N b}^{1}$ & & $\delta_{N b}^{b}$ \\
\hline 1 & & 0 & & 1 & 1 & 0 & $\cdots$ & 1 & 0 & 0 \\
\hline
\end{tabular}

c) Codification for phase balancing

Figure 3. Codification to represent the DSPP.

the number of nodes with candidate substations, $d$ is the number of available types of substations, $N_{b}$ is the number of system nodes and $b$ corresponds to the number of possible phase balancing per node.

\section{Formulation of POLARDS}

To represent the POLARDS for fault isolation and load transference a multi-objective mixed nonlinear integer mathematical model is used, wich objective functions are the minimization of NSEL and the cost of installation of reclosers. To develop this model, a reduction of the network is performed through a single-phase equivalent, over which the impact of the permanent faults of the NSEL are estimated [7].

$$
\begin{gathered}
\min z_{2} \sum_{y \in \Omega_{Y}}\left[\left(\sum_{k \in \Omega_{y N}} P_{k, y}\right)\left(\sum_{i j \in \Omega_{y L}} \lambda_{i j, y} \cdot L_{i j, y} \cdot r_{i j, y}\right)\right] \\
\min z_{3}=\sum C_{m} \cdot x_{m}
\end{gathered}
$$

s.t.

$$
\begin{gathered}
E Q^{u}\left(P_{k}^{D}, Q_{k}^{D}, V_{k}, \theta_{k}\right)=0 \quad \forall k \in \Omega_{k} \\
\left|I_{i j}^{c}\right| \leq I_{i j}^{c, \max } \quad \forall i j \in \Omega_{i j} \\
V_{k}^{\min } \leq V_{k} \leq V_{k}^{\max } \quad \forall k \in \Omega_{k}
\end{gathered}
$$

Equations (11) and (12) represent the minimization of the NSEL and the minimization the investment costs in automatic reclosers, respectively. In the set of constraints, equation (13) corresponds to the power balance at each node in the system, equations (14) and (15) correspond to the compliance of the chargeability limits of lines and voltage regulation at all nodes of the system, respectively. Constraints of number of reclosers or maximum investment limit are not considered, because being a multi-objective problem, the solution that meets the most of the requirements of the network operator is chosen from the Pareto front [8].

\section{Solution technique for POLARDS}

To solve the POLARDS, according to the multiobjective formulation described, the NSGA II optimization algorithm is used (see Figure 4) [16], so as compared with other techniques for multi-purpose solution, it has better computing performance, obtaining higher quality responses [17].

This technique is attractive because it has two fundamental characteristics: population diversity is ensured during the process solution through the inclusion of genetic operators of selection, recombination and mutation, and it is an elitist algorithm, which means that only the best solutions found in different Pareto fronts are considered during the process, through the implementation of the dominance criteria $[8,18-20]$.

\section{Initial configuration}

In order to represent adequately the POLARDS for fault isolation and load transfer, consider the distribution system presented in Figure 5. There is a set of network sections as candidates for the location of NCR and NOR, which are selected by using a route network heuristic algorithm [11]. So, to select possible location points of NCR, a route is performed from each end node of the system to their respective substation, identifying the network sections with at least two branches, finally, each network segment located downstream from the bifurcation is selected as a candidate for the location of NCR [19-20].

On the other hand, to select the candidates network sections for the location of NOR all the lines that do not belong to the current configuration are chosen, that is, the disconnected network sections that link 


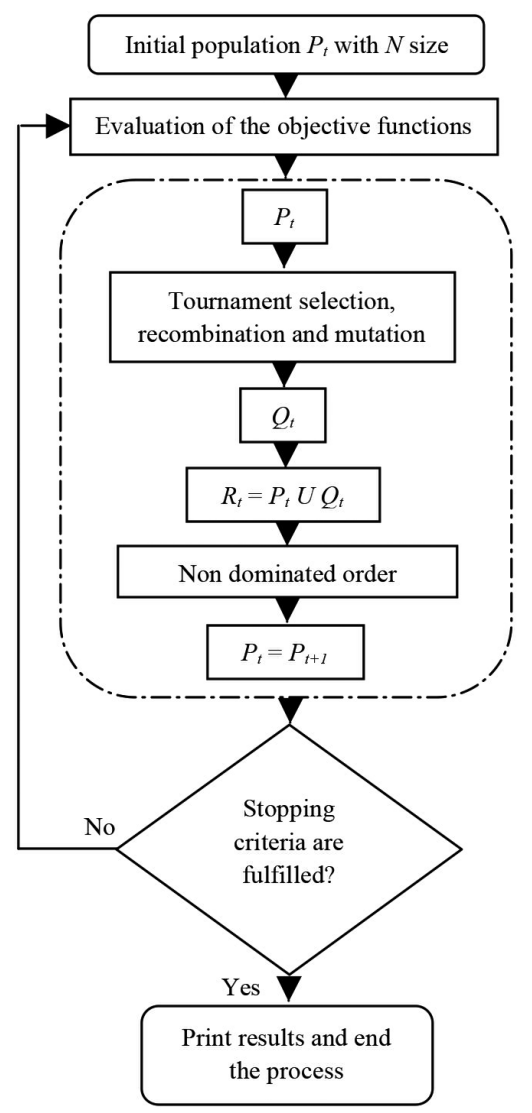

Figure 4. NSGA II algorithm.

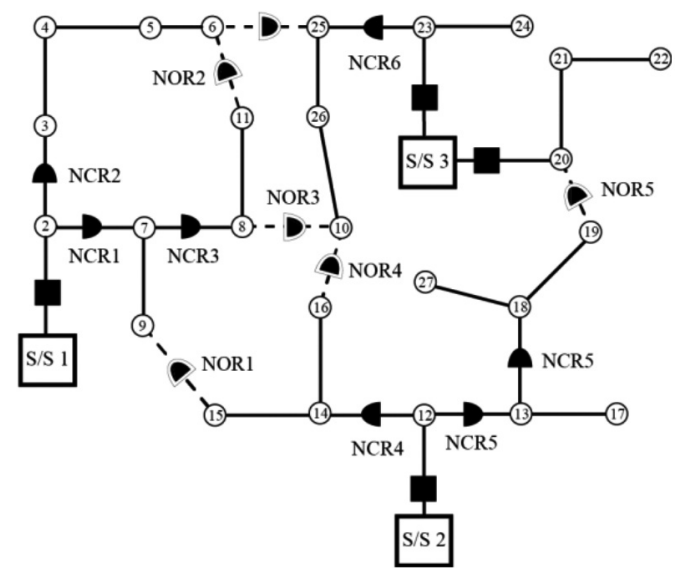

Figure 5. Possible locations for NOR and NCR in a distribution network.

two different substations, in order to ensure the possibility of load transfer under the presence of permanent faults [11].

\section{Problem codification}

To represent the location of NCR and NOR in distribution systems, a binary vector codification consisting of two sections is used [8]. The first section corresponds to the possible location points of NCR and the second section overcomes the candidate points to the location of NOR. Thus for the scheme presented in Figure 5, there are six points with NCR and five points with NOR located.

In Figure 6, the codification used is presented assuming that the topology of a distribution system can count with $\mathrm{m}$ candidate points for the location of NCR and $n$ candidate points for the location of NOR, so, the overall size of vector codification is $n+m$.

\begin{tabular}{|c|c|c|c|c|c|c|c|c|c|}
\hline \multicolumn{1}{|c|}{ NOR } & \multicolumn{1}{c|}{ NOR } \\
\hline 1 & 0 & $\cdots$ & 0 & 1 & 1 & 0 & $\cdots$ & 1 & 0 \\
\hline
\end{tabular}

Figure 6. Proposed codification for POLARDS.

\section{Selection of a configuration on Pareto front}

The NSGA II algorithm is a multi-objective optimization technique that provides a set of solutions called optimal Pareto front. This front corresponds to a tradeoff between the objectives [8]. In POLARDS, this implies that the improvement of one objective degrades the other one, as shown in Figure 7.

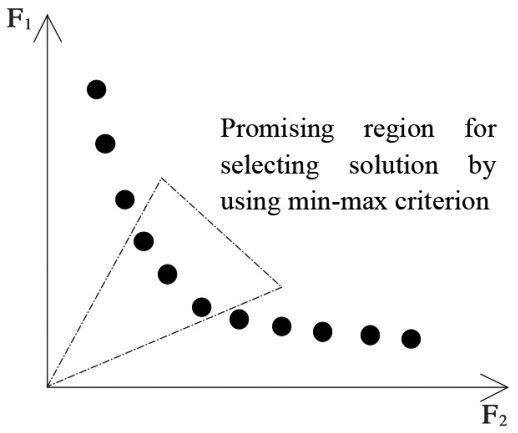

Figure 7. Possible Pareto front for two-objective minimization.

To select a solution on the optimal Pareto front of Figure 7, the criterion known as max-min is used as shown in equation (16) [21]. 
$\operatorname{máx}\left\{\min \left\{\frac{F_{1-\text { máx }}-F_{1-i}}{F_{1-\text { máx }}-F_{1-\text { min }}}, \frac{F_{2-\text { máx }}-F_{2-i}}{F_{2-\text { máx }}-F_{2-\text { min }}}\right\}\right\}$

Where $F_{1-\operatorname{máx}}, F_{1-\min }, F_{2-\text { máx }}$ and $F_{2-\min }$ correspond to the maximum and minimum values of the objective functions 1 and 2, respectively; $F_{1-i}$ and $F_{2-i}$ correspond to the value of both objective functions for each point on the front.

In Figure 7 is observed that when applying this metric to a two-objective minimization problem, the possible selected point corresponds to the central region of the front, because the extreme points represent an objective preference over the other one.

\section{PROPOSED METHODOLOGY}

In this section, two methodologies to solve the DSPP in conjunction with the POLARDS are proposed. In order to compare the results obtained through both methods, an economic analysis of the expansion of the distribution system in the presence of NCR (for faults isolation) and NOR (for transfer load) is performed. In this analysis, a horizon of static planning for cost evaluation of power losses and investment in network elements in terms of their net present value and annual NSEL is considered (see Figure 8).

\section{Cascade methodology}

The cascade model aims to solve the DSPP through the methodology proposed in section "Distribution system planning problem formulation" to find the optimal topology of the distribution system. After obtaining a set of solutions of the elite list, the methodology proposed in section "Location of automatic reclosers problem formulation" is applied to locate NCRs and NORs on the set of topologies contained in the elite list and finally a point on the optimal Pareto front through max-min criterion is selected [21], for each of them. The optimal solution will be the one with the lowest overall cost of investment and operation. It is necessary to take into account that this methodology is of unidirectional application as to the selection of the optimal POLARDS configuration is essential to know the topology of the distribution system.

\section{Integrated methodology}

In this methodology the inclusion of POLARDS as a function of DSPP is proposed. In other words, the

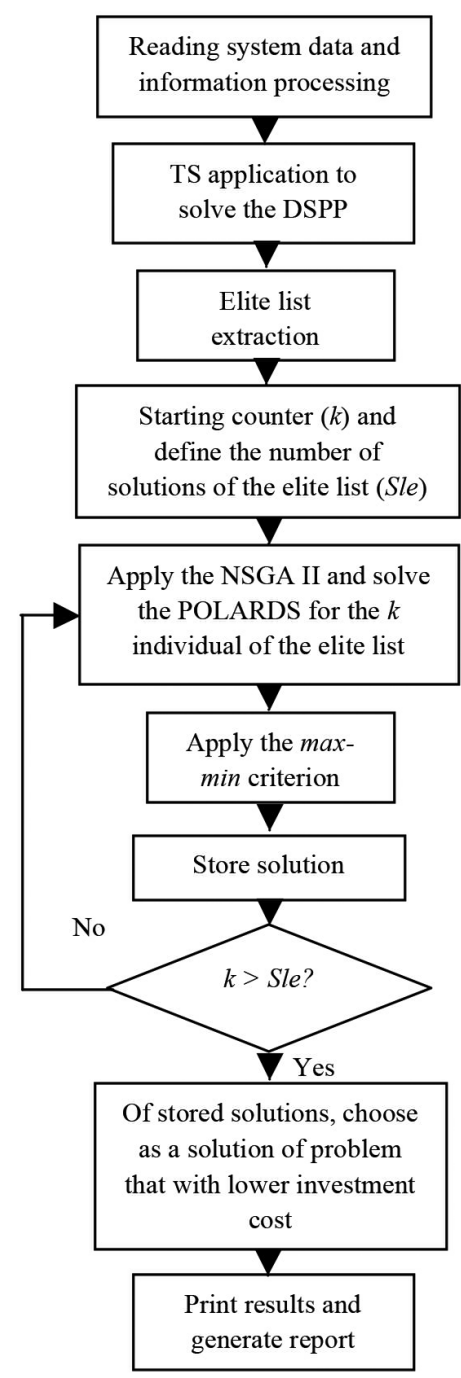

Figure 8. Cascade methodology.

integrated model proposes that for each neighbor (generated through the application of TS algorithm over the DSPP), an evaluation of POLARDS has to be performed through NSGA II algorithm and the selection of a configuration for NCR and NOR is done by employing the max-min criterion. Under this scenario, each local search developed by the TS algorithm will provide to the elite list of global solutions, the best network topology found (types and locations of substations, branches and wires gauges), with the location of NCR for fault isolation and NOR for load transfer (see Figure 9).

It is necessary to point out that the best solution found, is that with the following characteristics: 


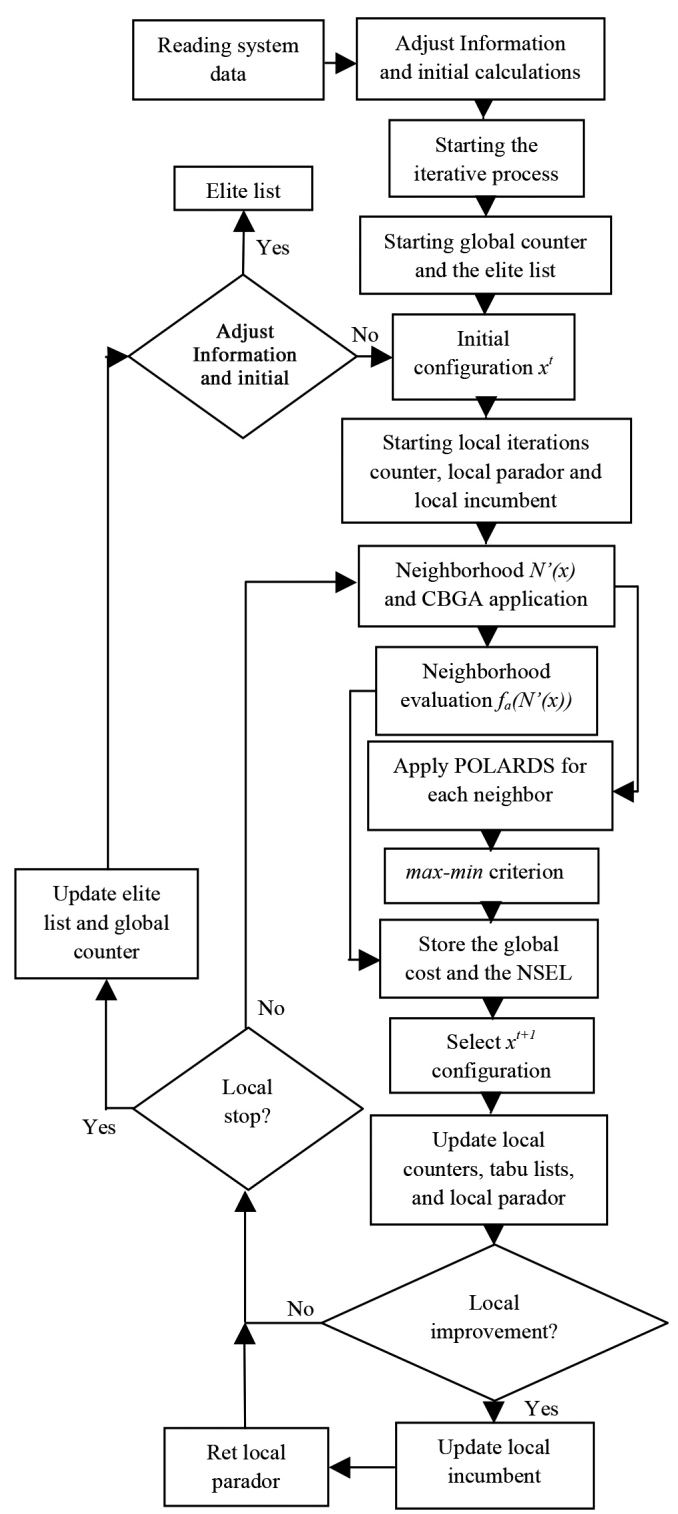

Figure 9. Integrated methodology.

the lowest investment costs in both, the network equipment and the operating costs of power loss during the study period; and the NSEL working as an indicator of quality service on the network, under a likely scenario of average fault rates and repair times (not quantified economically).

\section{TEST AND RESULTS}

The optimization algorithm developed in this work was implemented on a computer with Windows 7 professional OS, Intel Core i3 processor, 4GB RAM, using the MATLAB 2014 software, licensed by the Universidad Tecnológica de Pereira for academic and research purposes.

To demonstrate the efficiency and robustness of the proposed methodologies, a three-phase unbalanced 36-node test feeder is analyzed, based on modifications of the IEEE 34-node test feeder, as shown in Figure 10, where a different power factor is assigned at each node.

There are 6 branches (solid lines) connected to the substation located at node 1 and 44 new network sections (dashed lines) and two substations at the nodes 35 and 36 (dotted square) are proposed for network expansion. The current system demand for phases $b$ and $c$ is $1.85 \mathrm{MVA}$ and 1.03 MVA, respectively. Phase $a$ has no load connected. The 29 nodes with new demand (8-36) have a total charge for phases a, b and c, in Wye connection, of 2.68 MVA, 2.04 MVA and 1.45 MVA, respectively, and a total charge per phase in delta connection with 1.97 MVA, 2.11 MVA and 2.66 MVA, respectively. The load is modeled as constant power $(80 \%)$ and constant impedance (20\%). The line-to-line voltage level is rated $14.4 \mathrm{kV}$ and the maximum allowable voltage variation is $5 \%$. The study period considered is 20 years. Data lines and loads can be consulted in [11].

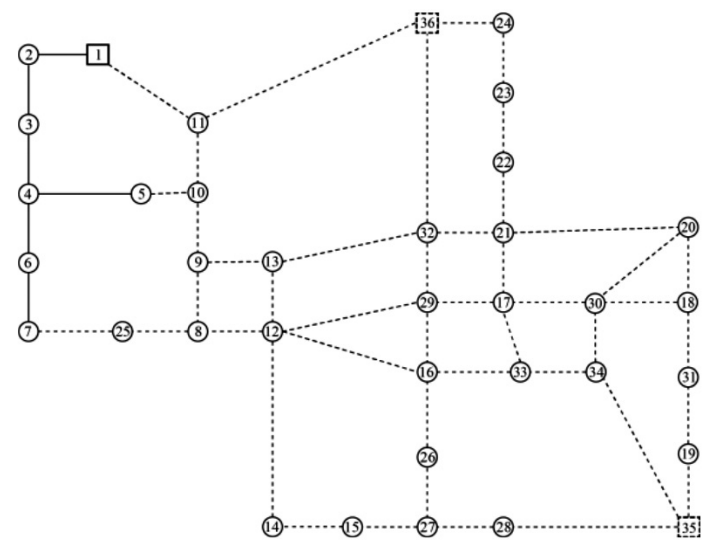

Figure 10.36-nodes test feeder.

In Tables 1 to 4 the general aspects employed in the computational implementation are presented. 
Table 1. Costs, interest rates and parameters.

\begin{tabular}{|l|c|}
\hline \multicolumn{1}{|c|}{ Parameter } & Value \\
\hline Maximum voltage regulation & $5 \%$ \\
\hline Interest rate & $10 \%$ \\
\hline Growth rate of energy cost & $2 \%$ \\
\hline Cost of phase balance & US\$ 8 \\
\hline Cost of energy & 100 USD $/ \mathrm{MWh}$ \\
\hline Planning period & 20 years \\
\hline Reclosers cost & $\$ 20,000$ \\
\hline
\end{tabular}

Table 2. Costs of conductors types.

\begin{tabular}{|c|c|c|c|c|c|c|c|}
\hline \multirow{2}{*}{ Type } & \multirow{2}{*}{$\begin{array}{c}\text { Maximum } \\
\text { current [A] }\end{array}$} & \multicolumn{6}{|c|}{$\begin{array}{c}\text { Costs of installation and } \\
\text { increasing caliber [kUSD\$/km] }\end{array}$} \\
\cline { 3 - 8 } & & $\mathbf{1}$ & $\mathbf{2}$ & $\mathbf{3}$ & $\mathbf{4}$ & $\mathbf{5}$ & $\mathbf{6}$ \\
\hline 1 & 150 & 20 & 23 & 37 & 40 & 58 & 76 \\
\hline 2 & 250 & - & 30 & 30 & 35 & 50 & 66 \\
\hline 3 & 350 & - & - & 42 & 29 & 43 & 53 \\
\hline 4 & 400 & - & - & - & 50 & 35 & 45 \\
\hline 5 & 500 & - & - & - & - & 67 & 38 \\
\hline 6 & 600 & - & - & - & - & - & 85 \\
\hline
\end{tabular}

Table 3. Costs of substations types.

\begin{tabular}{|c|c|c|c|c|c|}
\hline \multirow{2}{*}{ Type } & \multirow{2}{*}{$\begin{array}{c}\text { Power } \\
\text { capacity } \\
{[\text { [MVA] }}\end{array}$} & \multicolumn{4}{|c|}{$\begin{array}{c}\text { Costs of installation and } \\
\text { increasing capacity [USD\$] }\end{array}$} \\
\cline { 3 - 6 } & & $\mathbf{1}$ & $\mathbf{2}$ & $\mathbf{3}$ & $\mathbf{4}$ \\
\hline 1 & 5 & 675 & 675 & 1,350 & 2,025 \\
\hline 2 & 10 & - & 1,350 & 675 & 1,350 \\
\hline 3 & 15 & - & - & 2,025 & 675 \\
\hline 4 & 20 & - & - & - & 2,700 \\
\hline
\end{tabular}

Table 4. Discretization periods of duration of annual load curve.

\begin{tabular}{|c|l|c|c|}
\hline Level & Load & Duration [h] & Load level [\%] \\
\hline 1 & Maximum & 1,000 & 100 \\
\hline 2 & Mean & 6,760 & 60 \\
\hline 3 & Minimum & 1,000 & 30 \\
\hline
\end{tabular}

\section{Cascade methodology results}

The obtained topology after applying this methodology is presented in Figure 11. The results show that the system is powered by two substations, where substation 1 is rated initially with a capacity of 5 MVA and the new substation, in node 36, has an installed capacity of 15 MVA. Furthermore, in the solution, it is noted that only two automatic reclosers appear. The NCR located at branch 32-29 divides the feeder in two areas and the NOR located in the branch 14-15 interconnects both subsystems for load transfer.

Overall costs associated with optimal topology found by the cascade methodology are presented in Table 5.

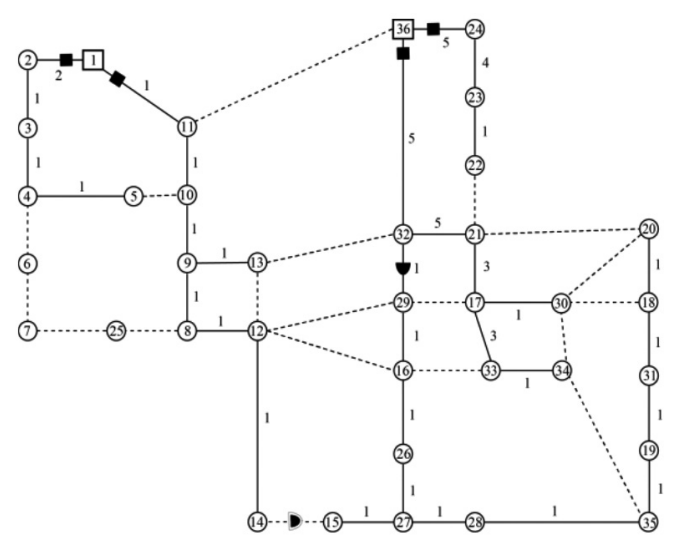

Figure 11. Optimal topology found by cascade methodology.

Table 5. Net present value (NPV) of solutions for cascade methodology.

\begin{tabular}{|l|r|}
\hline \multicolumn{2}{|c|}{ Global Costs [USD\$] } \\
\hline Conductors & $76,286.04$ \\
\hline Power loss & $69,060.72$ \\
\hline Substations & $2,025,000.00$ \\
\hline Reclosers & $44,001.96$ \\
\hline Phase balance & 240.00 \\
\hline Total costs & $2,214,588.72$ \\
\hline
\end{tabular}

\section{Integrated methodology results}

The obtained topology after applying this methodology is presented in Figure 12. Overall costs associated with optimal topology found by the integrated methodology are presented in Table 6 .

It is noteworthy, that unlike the previous case, the system is powered by three substations, where substation 1 has an initial capacity of 5 MVA and new substations located at nodes 35 and 36 have capacities of 10 MVA and 5 MVA respectively. By the other side, in the solution, the presence of only two automatic reclosers such as in the previous case. 


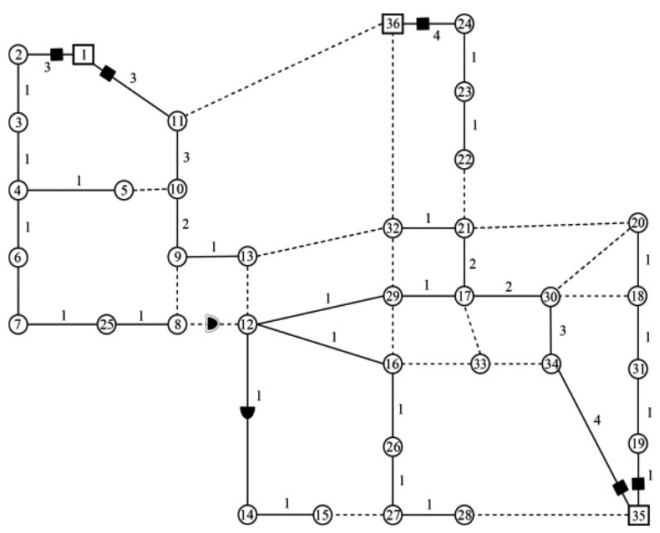

Figure 12. Optimal topology found by integrated methodology.

The NCR located in the branch 12-14 and the NOR located in the branch 8-12, interconnect subsystems formed by substations of node 1 and node 35 .

Table 6. Net present value (NPV) of solutions for integrated methodology.

\begin{tabular}{|l|r|}
\hline \multicolumn{2}{|c|}{ Global Costs [USD\$] } \\
\hline Conductors & $73,752.24$ \\
\hline Power loss & $51,192.17$ \\
\hline Substations & $2,025,000.00$ \\
\hline Reclosers & $44,001.79$ \\
\hline Phase balance & 208.00 \\
\hline Total costs & $2,142,962.04$ \\
\hline
\end{tabular}

\section{Discussion of results}

According to the answers presented in Figure 11 and Figure 12, it is clear that every proposed methodology guides the evolutionary process of the algorithm through a different path inside the solution space. Under this scenario and analyzing the system of Figure 11, the best solution obtained by the cascade methodology, corresponds to a configuration with two substations; while for the topology of Figure 12, the optimal topology found by integrated methodology, corresponds to a distribution system with three substations.

On the other hand, both solutions have as common feature, a load transfer through a NOR and an automatic switching point for fault isolation given by a NCR.
Additionally, according to Tables 5 and 6 it is observed that when the load is distributed in different substations for a distribution system, the level of power loss is lower during the study period, which is why the investment cost also decreases, because the caliber of each network segment is reduced according to the current reduction provided by the distribution of load.

It is noted that although the topologies found by each methodology are strictly different, the investment cost is directly related to the expansion or construction of new substations and that, according to Tables 5 and 6 , this cost corresponds to more than $90 \%$ of the total plan for the proposed test feeder.

For both methodologies, the strategy of phase balancing in distribution system planning helps to achieve minimum levels of power loss with a very low investment. This projects the strategy as a lowcost tool with impact on the operative state of the system, in terms of voltage regulation and quality of service for the end user, guaranteeing benefits (provided by regulator entities) to the utilities, by the fact of having an electrical system that contributes to the efficient use of energy.

By making an analysis, in terms of the Equivalent Uniform Annual Cost (EUAC) to the project cost, it is observed that the cascade methodology during the study period, requires an annual investment of US $\$ 260,124.76$; while for the integrated methodology, the investment is US \$251,711.51, which means that, taking as reference the cascade methodology case, the integrated methodology achieves a reduced level of investment.

Considering that both systems need one NCR and one NOR to reduce the NSEL, with the cascade methodology an annual NSEL of $1,247.46 \mathrm{GWh}$ is obtained, while the integrated methodology approach reaches an annual NSEL of 1,103.56 GWh. In percentage terms, taking as a reference the cascade methodology, the integrated model achieves an annually reduction of $11.54 \%$.

\section{CONCLUSIONS}

Two methodologies for distribution systems planning were developed, considering the optimal location of automatic reclosers for fault isolation and load 
transfer. The first methodology corresponds to a cascade model that solves the classical problem of distribution system planning by using a TS algorithm and the solutions contained in the elite list are applied over a NSGA II. The max-min criterion is employed to find the best tradeoff between investment cost and NSEL. The second methodology proposes a master-slave based solution algorithm to solve both problems in an integrated manner, in which the master algorithm is the TS and the slave algorithm is the NSGA II, which guides the solution process by a different path in comparison with the methodology.

In light of the obtained results, for solving the problem of optimal distribution systems planning in conjunction with the optimal location of automatic reclosers to improve indicators of reliability, the integrated methodology has better quality results in terms of overall investment cost and NSEL of the system.

The developed mathematical models to solve both problems are closely related to the nature of the Colombian electrical systems, as these are highly unbalanced, with problems of quality of service in terms of continuity. So this work is proposed as a strategy of wide applicability for all electricity utilities in Colombia.

\section{ACKNOWLEDGMENT}

This work was supported by the Universidad Tecnológica de Pereira (Colombia) under Internal Project 6-13-4, and the Young Research Program of the National Department of Science, Technology and Research (COLCIENCIAS) of Colombia (JI6-13-6).

\section{REFERENCES}

[1] S.A. Milocaa, N.M.P. Volpib, J. Yuanb and C.L.S. Pinto. "Expansion planning problem in distribution systems with reliability evaluation: An application in real network using georeferenced database". International Journal of Electrical Power \& Energy Systems. Vol. $70 \mathrm{~N}^{\circ} 1$, pp. 9-16. September, 2015. DOI: 10.1016/j.ijepes.2015.01.004

[2] E.M. de Almeida and E.N. Asada, "NSGA-II applied to the multi-objective Distribution System Expansion Planning problem",
Intelligent System Application to Power Systems (ISAP), 2015 18th International Conference on, Porto, 2015, pp. 1-6. DOI: 10.1109/ISAP.2015.7325570.

[3] M. Ippolito, E. Sanseverino, and F. Vuinovich. "Multiobjective ant colony search algorithm optimal electrical distribution system planning". Congress on Evolutionary Computation. CEC2004. Portland, USA. 2004.

[4] I.J. Ramírez and J.A. Domínguez. "New multiobjective tabu search algorithm for fuzzy optimal planning of power distribution systems". IEEE Transactions on Power Systems. Vol. $21 \mathrm{~N}^{\circ}$ 1, pp. 224-233. February, 2006. ISSN: 0885-8950. DOI: 10.1109/ TPWRS.2005.860946

[5] C.A. Peñuela, "Desenvolvimento de técnicas e modelos matemáticos para solução do problema de planejamento da expansão e operação de sistemas de distribuição de energia elétrica com geradores distribuidos". Ph.D. dissertation, Universidad Estadual Paulista "Julio de Mesquita Filho". Facultade de Engenharia. São Paulo, Brasil. 2012. Visited on April 2014: http://www.feis.unesp. br/Home/departamentos/engenhariaeletrica/ lapsee/2012_tese_cesar_penuela.pdf

[6] N. Sahoo, S. Ganguly and D. Das. "Multiobjective planning of electrical distribution systems incorporating sectionalizing switches and tie-lines using particle swarm optimization". Swarm and Evolutionary Computation. Vol. 3, pp. 15-32. December, 2011. DOI: 10.1016/j.swevo.2011.11.002

[7] O.D. Montoya, A. Grajales, R.A. Hincapié, M. Granada and R.A. Gallego. "Methodology for optimal distribution system planning considering automatic reclosers to improve reliability indices". 2014 IEEE PES Transmission \& Distribution Conference and Exposition - Latin America (PES T\&DLA). Medellin, Colombia. 2014.

[8] O.D. Montoya, R.A. Hincapié and M. Granada. "A new approach to optimal allocation of reclosers in distribution systems considering service quality and fixed costs". Ingeniare, Revista Chilena de Ingeniería. Vol. $24 \mathrm{~N}^{\circ}$ 1, pp. 55-69. 2016. ISSN: 0718-3305. DOI: dx.doi.org/10.4067/ S0718-33052016000100006 
[9] L.P. Pérez Hernández, J.F. Franco y R.A. Gallego. "Planeamiento de sistemas de distribución usando búsqueda tabú". Revista Ingeniería y Ciencia. Vol. $13 \mathrm{~N}^{\circ} 34$, pp. 85-90. Mayo, 2007. ISSN: 0122-1701

[10] M. Granada, R.A. Gallego and J.M. Lezama. "Planeamiento Óptimo de Balance de Fases para Reducción de Pérdidas en Sistemas de Distribución usando un Algoritmo Genético Especializado". Revista Ingeniería y Ciencia. Vol. 8 N$^{\circ} 15$, pp. 121-140. June, 2012. ISSN: 1794-9165

[11] O.D. Montoya. "Optimal Distribution System Planning Considering Automatic Reclosers to fault isolation and load transfer". M.Sc. dissertation, Universidad Tecnológica de Pereira. Facultad de Ingeniería. Pereira, Colombia. 2014. Visited on May 2015: http:// repositorio.utp.edu.co/dspace/bitstream/ handle/11059/4253/621319M798P. pdf? sequence $=1 \&$ is Allowed $=y$

[12] A.T. Pozos, M.L. de Oliveira, J.F.F. Baquero and M.J.R. Flores, "A mixed-binary linear formulation for the distribution system expansion planning problem", Transmission \& Distribution Conference and Exposition Latin America (PES T\&D-LA), 2014 IEEE PES, Medellin, 2014, pp. 1-6. DOI: 10.1109/ TDC-LA.2014.6955275

[13] F. Glover. "Tabu search fundamentals and uses", pp. 1-85. 1995. Visited on November 2014. URL: http://leedsfaculty.colorado.edu/glover/TS $\% 20-\% 20$ Fundamentals\%26Uses.pdf

[14] M. Lavorato, M.J. Rider, and A.V.G.R. Romero. "A constructive heuristic algorithm for distribution system planning". IEEE Transactions on Power Systems. Vol. 25, pp. 1734-1742. August, 2010. ISSN: 0885-8950. DOI: 10.1109/TPWRS.2009. 2038164
[15] D. Shirmohammadi, H.W. Hong, A. Semlyen and G. X. Luo. "A compensation based power flow method for weakly meshed distribution and transmission networks". IEEE Transactions on Power Delivery. Vol. 3 $\mathrm{N}^{\circ}$ 2, pp. 753-762. May, 1988. ISSN: 08858950. DOI: $10.1109 / 59.192932$

[16] K. Deb, A. Pratap, S. Agarwal and T. Meyarivan. "A fast and elitist multi-objective genetic algorithm: NSGA-II". IEEE Transactions on Evolutionary Computation. Vol. 6, pp. 182-197. April, 2002. ISSN: 1089-778X. DOI: 10.1109/4235.996017

[17] C.A.C. Coello, D.A.V. Veldhuizen and G.B. Lamont. "Evolutionary algorithms for solving multi-objective problems". Springer US. 2nd edition, pp. 59-179. New York, USA. ISSN: 1932-0167. DOI: 10.1007/978-0-387-36797-2

[18] C.A. Pulgarín, M. Ríos, C.A. Acosta, R.A. Hincapié, M. Granada, R.A. Gallego. "Localización óptima de reconectadores normalmente abiertos para la transferencia de carga". Revista Mundo Eléctrico. № 90 , pp. 38-44. 2013.

[19] O.D. Montoya, A. Arias, R.A. Hincapié, and M. Granada, "Optimal location of reclosers by using MOEA SPEA II". Simpósio Brasileiro de Sistemas Elétricos. Foz do Iguaçu, Paraná, Brasil. 2014.

[20] A.F. Alzate, O.D. Montoya, R.A. Hincapié and M. Granada. "Optimal location of reclosers in distribution systems considering reliability in communication channels". IEEE 6th Latin American Symposium on Circuits \& Systems (LASCAS). Montevideo, Uruguay. 2015.

[21] R.I. Bolaños, R.A Hincapié and R.A. Gallego. "Reubicación óptima de transformadores de distribución usando el algoritmo multiobjetivo de optimización NSGA II". Revista Ingeniería y Ciencia. Vol. 10 N$^{\circ}$ 19, pp. 77-97. 2014. ISSN: 1794-9165. 